\title{
Gerd Kohlhepp e as heranças da geografia alemã para os estudos de colonização e desenvolvimento no Brasil
}

\section{Entrevista:}

Entrevista com o geógrafo alemão Gerd Kohlhepp ${ }^{1}$ concedida ao Editor Chefe de HALAC, Prof. Sandro Dutra e Silva ${ }^{2}$ (Anápolis, Goiás, Brasil, em 24 de outubro de 2018), com introdução de Stephen Bell ${ }^{3}$.

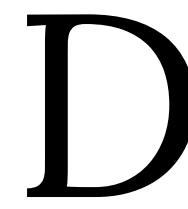
esde muito tempo que eu nutro um profundo e pessoal envolvimento com a geografia histórica do sul e centro-sul do Brasil. Após o meu primeiro encontro com o Prof. Sandro Dutra e Silva em Portugal no ano de 2014 - em decorrência da Segunda Conferência Mundial de História Ambiental, realizada na cidade de Guimarães -, tive a oportunidade de visitar Goiás naquele mesmo ano a convite dele. Em Anápolis eu pude reconhecer, particularmente, mas de maneira visceral, o quanto o geógrafo alemão Leo Waibel conseguiu transmitir as características distintas da geografia e das paisagens do centro-oeste brasileiro,

\footnotetext{
1 Dr. Phil in Geography, University of Heidelberg, Germany. Professor Emeritus, University of Tübingen, Germany. ORCID: https://orcid.org/00000001-5087-2462. gerd.kohlhepp@t-online.de

2 PhD in History, University of Brasilia, Brazil. Professor of History, Universidade Estadual de Goiás, and Centro Universitário de Anápolis, Brazil. ORCID: https://orcid.org/0000-0002-0001-5726. sandrodutr@hotmail.com

$3 \mathrm{PhD}$ in Geography, University of Toronto, Canada. Professor of Geography and History, University of California, Los Angeles. ORCID: https://orcid.org/0000-0003-3411-2329. dunsop@gmail.com
} 
apesar das limitações, com um tempo relativamente curto e estadia para as suas publicações. Na visita eu tive a oportunidade de discutir com meu anfitrião, o Prof. Dutra e Silva, o meu interesse na história intelectual da geografia alemã e brasileira. Mais tarde, sugeri a ele, baseado em parte em nossa consciência compartilhada da importância das pesquisas geográficas alemãs anteriores, que seria pertinente um convite para que o Prof. Gerd Kohlhepp visitasse Goiás. Inicialmente, essa visita ficou planejada para uma conferência científica que havia ocorrido em Anápolis no mês de outubro de 2017, e que reuniria três estudiosos fascinados por experiências com os estudos comparados sobre a fronteira. Infelizmente a vinda do Prof. Kohlhepp não foi possível, apesar da abundância de boa vontade. Mas eu fiquei verdadeiramente encantado ao saber que em 2018 o Prof. Kohlhepp estaria em Goiás, apesar de que, naquela oportunidade eu já não poderia participar. A presente entrevista é, portanto, um impressionante resultado daquela visita.

Assim como Gerd Kohlhepp, meu objeto de pesquisa de doutoramento começou com os estudos sobre o sul do Brasil. Mesmo assim, nossos trabalhos apresentam semelhanças e diferenças. A entrevista a seguir, por exemplo, demonstra a profunda satisfação de Kohlhepp ao reconhecer que apenas recentemente o seu substancial estudo em alemão sobre o norte do Paraná havia sido traduzido para uma impressionante edição brasileira. Já o meu livro sobre o sistema pecuário de produção, da região de Campanha, no extremo sul do Brasil, aguarda uma tradução para a língua portuguesa ${ }^{4}$. Enquanto o enfoque principal dos estudos de Kohlhepp foi a região de Santa Catarina e Paraná, o meu dizia respeito ao Rio Grande do Sul. A título de contexto, iniciei meu interesse sobre o sul do Brasil a partir da Universidade de Toronto, trabalhando sob a supervisão do Prof. J.H. Galloway, uma autoridade, acima de tudo, sobre a geografia histórica do açúcar, e um contemporâneo de Kohlhepp na bolsa geográfica internacional referente ao Brasil. Prof. Galloway foi um ex-aluno do eminente geógrafo histórico britânico H.C. (Sir Clifford) Darby, um pesquisador conhecido por Gottfried Pfeifer - que havia sido o mentor de Kohlhepp -, principalmente por meio de contribuições separadas, extraídas de um grupo internacional interdisciplinar composto por apenas setenta estudiosos, integrados 
pelo projeto patrocinado pela Fundação Wenner-Gren em 1955 (Man's Role in Changing the Face of the Earth), com enfoque no massivo papel dos seres humanos na transformação das paisagens terrestres ${ }^{5}$. Este projeto foi um marco importante por ter realizado uma avaliação pioneira em larga escala do que estava acontecendo no planeta em decorrência da ação antrópica, fundamental para o emergente campo da história ambiental.

Durante o meu doutoramento eu pude ler uma importante literatura geográfica internacional sobre o sul do Brasil. Destaco as contribuições que incluíram estudos como o do geógrafo francês Jean Roche sobre a colonização alemã no Rio Grande do Sul. Também fiquei fascinado pela franqueza e clareza de como Leo Waibel expôs seu trabalho sobre problemas de colonização no sul do Brasil. Esses já eram, no entanto, obras de uma geração anterior de estudiosos. Também li em alemão o trabalho recente de Gerd Kohlhepp sobre o norte do Paraná ${ }^{6}$ e fui imediatamente atraído pela qualidade da pesquisa, mais diretamente para a análise cartográfica. Sob a supervisão do Prof. Galloway eu tive uma experiência acadêmica muito bem fundamentada, principalmente em questões relacionadas à emergente literatura sobre o Brasil. Eu me lembro de uma ocasião no qual eu tive a oportunidade de discutir com meu supervisor os pontos fortes do trabalho do Prof. Kohlhepp em minha opinião, e ouvi do Prof. Galloway uma veemente afirmação de que eu deveria escrever e entrar em contato com ele. Eu não fiz isso, na época por ser conta de minha exigente reserva britânica. Mas algum tempo depois, antes da conclusão da minha tese de doutorado em 1991, eu o visitei, sem aviso prévio, em seu escritório em Tübingen. Foi uma reunião a qual eu trago comigo na lembrança. Chamou-me a atenção de que ele me levou a sério e passamos muito tempo discutindo a geografia do sul do Brasil. Em 1992, eu o visitei brevemente no Instituto Geográfico de Tübingen, onde ainda eu dei uma palestra em geografia histórica sobre os sistemas da escravidão na economia pecuária do Rio Grande do Sul do século XIX. Uma das principais lições extraídas dessa breve visita foi o puro dinamismo dos contatos com o Brasil. Em minha opinião é lamentável que o força cinética impulsionada por Kohlhepp e por muitos outros

\footnotetext{
${ }^{5}$ William L. Thomas Jr. et al., Man's Role in Changing the Face of the Earth (Chicago: University of Chicago Press, 1956).

6 Gerd Kohlhepp, Agrarkolonisation in Nord-Paraná. Wirtschafts- Und Sozialgeographische Entwicklungsprozesse Einer Randtropischen Pionierzone Brasiliens Unter Dem Einfluss Des Kaffeeanbaus, vol. 41, Heidelberger Geographische Arbeiten (Wiesbaden: Franz Steiner-Verlag, 1975).
} 
pesquisadores visitantes da América Latina, não apenas do Brasil, não encontrou um cenário sustentável em Tübingen.

Na entrevista a seguir, um ponto de partida apresentado pelo Prof. Kohlhepp reforça que sua rica carreira geográfica referente à América Latina começou com uma bolsa de estudos concedida pelo Brasil. Certamente isso era algo incomum, considerando o local e época. O fenômeno do surgimento de "brasilianistas", pelo menos na América do Norte, surgiu essencialmente após 1964. Os pesquisadores internacionais que no início dos anos 1960 estudavam e trabalhavam no Brasil eram muito poucos. Essa foi uma vantagem para o Prof. Kohlhepp, de obter uma precoce e estreita colaboração com as eminentes autoridades geográficas brasileiras. Ele explica, no entanto, como ele momentaneamente frustrou-se em muitos dos seus estudos por ser ainda relativamente imaturo em pesquisa de campo relacionado à região de Santa Catarina. Isso me fez lembrar muito a minha experiência posterior no Rio Grande do Sul. Por mais desafiador que uma aprendizagem cultural possa parecer, é evidente que muita coisa fluiu das experiências de pesquisa do Prof. Kohlhepp no sul do Brasil, incluindo a possibilidade de seguir temas na geografia econômica de Santa Catarina no sentido mais amplo. Em sua rica e extensa bibliografia, considero as publicações sobre o sul do Brasil como de extrema importância, não apenas como contribuições para entender a dinâmica de uma ampla região - às vezes ainda pouco compreendida em toda a vastidão do restante do Brasil -, mas também para mostrar como os "brasileiros do sul" serviram como importantes agentes na ocupação e transformação do espaço em outras partes do país.

O Prof. Kohlhepp enfatiza nessa entrevista, compreensivelmente, a importância da região amazônica, pois ali ele desempenhou um papel significativo e que foi internacionalmente reconhecido. Estou ciente também, no entanto, do valioso trabalho que ele e seus alunos realizaram em outras regiões na América do Sul, como o centro-oeste brasileiro e leste do Paraguai. Gerd Kohlhepp mostra-se profundamente ciente de quanto o Brasil mudou ao longo de sua carreira. Seus interesses de pesquisa, dedicados muito à compreensão dos padrões emergentes de tempos e lugares atuais, parecem-me ter se desenvolvido amplamente em conjunto com a dinâmica regional transformadora no maior país tropical do mundo. 
Escrevo aqui principalmente como geógrafo histórico, sintonizado mais com o passado do que com o presente. A presente entrevista oferece janelas tentadoras para a história intelectual. O trabalho de Dutra e Silva é um bom exemplo de como os geógrafos pioneiros ainda são de importância seminal para dar sentido à história ambiental brasileira ${ }^{7}$. Gerd Kohlhepp construiu com distinção as contribuições dos primeiros geógrafos alemães, mais diretamente Leo Waibel e Gottfried Pfeifer. Por sua vez, Gerd Kohlhepp, como ele mesmo aponta, ganhou uma conexão muito mais profunda com a cultura brasileira do que os outros geógrafos jamais poderiam alcançar, mas ele está profundamente consciente acerca do valor e das limitações das contribuições dos seus antecessores. A geografia acadêmica brasileira está hoje abraçando as humanidades com vigor renovado. A Décima Sétima Conferência Internacional de Geógrafos Históricos, realizada em Varsóvia em 2018 (o próximo encontro mundial é projetado para o Rio de Janeiro em 2021), incluiu várias contribuições do Brasil, tratando aspectos da história da geografia acadêmica brasileira. Isso incluía estudos sobre a natureza do Décimo Oitavo Congresso Geográfico Internacional, realizado em 1956 no Rio de Janeiro, sob a coordenação do Prof. Hilgard O'Reilly Sternberg - a primeira ocasião em que um encontro mundial sob os auspícios da União Geográfica Internacional foi realizado no mundo tropical ${ }^{8}$.

Ao ler a entrevista a seguir, frequentemente me fazia refletir sobre o papel das colaborações intelectuais de um universo relativamente pequeno, porém rico, gerado pelas redes geográficas internacionais e o Brasil. Além da Alemanha e do Brasil, os Departamentos de Geografia da Universidade da Califórnia tiveram um importante papel, com destaque maior para o campus de Berkeley do que o mais novo colega institucional de Los Angeles. Waibel foi aluno de Alfred Hettner em Heidelberg. Carl Sauer, durante tanto tempo uma força intelectual motriz em Berkeley e em toda a geografia norte-americana, havia demonstrado a ambição anterior de estudar com Hettner, algo que ele era incapaz de realizar. Waibel e Sauer mantinham muitos interesses em comum sobre a América Latina. Eles também estavam em competição e não eram fáceis um para o outro, como revela claramente a correspondência entre

\footnotetext{
7 Sandro Dutra e Silva, No Oeste a Terra e o Céu: A Expansão Da Fronteira Agrícola No Brasil Central (Rio de Janeiro: Mauad X, 2017).

${ }^{8}$ Charles B. Hitchcock, "The Eighteenth International Geographical Congress, Rio de Janeiro, 1956," Geographical Review 47, no. 1 (1957): 11823.
} 
eles. Gottfried Pfeifer, destacado aluno de Waibel, mostrou uma promissora carreira acadêmica em Berkeley, até voltar em 1932 para Bonn, na Alemanha, para preparar seu trabalho de Habilitation. Visto em um nível muito geral, a abrangência intelectual e a profundidade com que os estudantes de pós-graduação alcançaram durante o mandato de Waibel no Instituto Geográfico de Bonn, encontram para mim algum tipo de comparação e semelhança com o que acontecia em Berkeley dos anos 1930. Bonn e Berkeley certamente figuravam entre os principais centros mundiais de investigação geográfica nesse período. Um dos estudantes de Sauer na década de 1930, em sua longa carreira em Berkeley, foi o alemão nascido em Berlim, Henry Bruman. Após pesquisas principalmente sobre o México colonial, ele continuou a desenvolver um interesse sustentado pelos assentamentos pioneiros brasileiros e pela pesquisa de fronteira, grande parte deles referente aos refugiados da Europa durante e após a Segunda Guerra Mundial. As anotações de campo de Bruman são ricas, descrevendo diferentes partes do Brasil, mas nenhuma com mais destaque do que o estado do Paraná, onde ele realizou trabalho de campo em várias ocasiões, a partir do início dos anos 50 .

A Universidade da Califórnia em Berkeley serviu por muito tempo como sede institucional do Prof. Hilgard O'Reilly Sternberg, cuja influência da orientação na carreira do Prof. Kohlhepp era seminal. Quando Henry Bruman tirou uma licença sabática em 1965 da UCLA para pesquisar no Brasil, foi o professor Orlando Valverde que veio do Brasil para o substitui-lo na California. Na entrevista a seguir, observamos como os círculos de interesse, com tanta frequência, se cruzam. Grande parte da história intelectual mais profunda, sobretudo em saber como as correntes de ideias fluíram entre as instituições e os continentes, ainda precisa ser investigada mais detalhadamente.

A corrente do trabalho geográfico alemão no Brasil encontrou em Waibel uma força pioneira, de que certa forma, e em uma escala diferente, também em Kohlhepp. Como ele observa em vários pontos, há uma consciência de como o mundo muda, incluindo a estrutura da academia. Existem muitos pontos de entrada na geografia do Brasil, um lugar que despertou minha curiosidade quando eu era estudante na Inglaterra dos anos 1970. Às vezes existem barreiras linguísticas substanciais a serem 
ultrapassadas. Mas quem quer ler a vasta literatura escrita no Brasil por Kohlhepp, seus mentores e alunos irão imergir em um mundo geográfico muito rico e estimulante. E mantenho, escrevendo como geógrafo histórico e historiador ambiental, que a grande maioria deste trabalho publicado manterá sua relevância por um longo tempo. Devo a Gerd Kohlhepp a mais profunda gratidão por seu incentivo, estímulo e amizade.

\section{SOBRE O ENTREVISTADO}

Gerd Kohlhepp nasceu em 21 de março de 1940, em Mannheim, Alemanha. Entre os anos de 1958 a 1962, Kohlhepp estudou geografia, geologia, economia, história e pré-história na Universidade de Heidelberg, onde também obteve o seu mestrado. Em 1972 foi habilitado em Geografia na Universidade de Heidelberg. Depois lecionou como professor de Geografia Humana na Universidade de Frankfurt até 1978. Posteriormente, passou a ser professor de Geografia Econômica e Social na Universidade de Tübingen, Alemanha. Em 2005 recebeu o título de professor emérito da Cátedra de Geografia Econômica e Social da Universidade de Tübingen.

Gerd Kohlhepp é uma referência em pesquisas sobre o processo de colonização agrícola no interior do Brasil. Os seus estudos sempre foram uma importante referência teórica e metodológica para os pesquisadores brasileiros, sobretudo para aqueles relacionados à colonização agrícola no Brasil.

Durante a passagem do geógrafo brasileiro Hilgard O'Reilly Sternberg por Heidelberg em 1961, Gerd Kohlhepp foi convidado para realizar seus trabalhos de doutoramento no Brasil. No Brasil Kohlhepp desenvolveu sua tese de doutoramento sobre a geografia industrial em Santa Catarina, realizando trabalhos de campo entre os anos de 1962/63 (Figura 01). Nessa pesquisa apresentou uma abordagem metódica inovadora para a geografia humana. Este estudo foi o ponto de partida para uma série de trabalhos sobre a geografia e a história econômica do Sul do Brasil. Em 1972, com a conclusão de sua pesquisa geográfica sobre o Brasil em Heidelberg - e com a aposentadoria de Pfeifer, que havia trabalhado com Leo Waibel em pesquisas sobre a geografia agrária no Brasil -, Kohlhepp foi convidado a assumir a cátedra de geografia 
humana na Universidade de Frankfurt. Em Frankfurt (1972-78) Kohlhepp iniciou suas pesquisas sobre a Amazônia em colaboração com pesquisadores de universidades brasileiras. Em 1978 ele foi nomeado como professor titular de geografia econômica e social na reconhecida Universidade de Tübingen, criando nesta universidade o "Centro de Pesquisas sobre a América Latina", no qual o Brasil ocupava papel privilegiado. O seu antecessor, Herbert Wilhelmy, um dos geógrafos mais renomados da Alemanha, já atuava em pesquisas sobre a América Latina, o que evidenciava a importância dessa região para a geografia alemã em Tübingen.

Figura 01. Ficha Consular de Qualificação, expedida em 1962, como visto temporário-especial para a realização de pesquisas no Brasil.

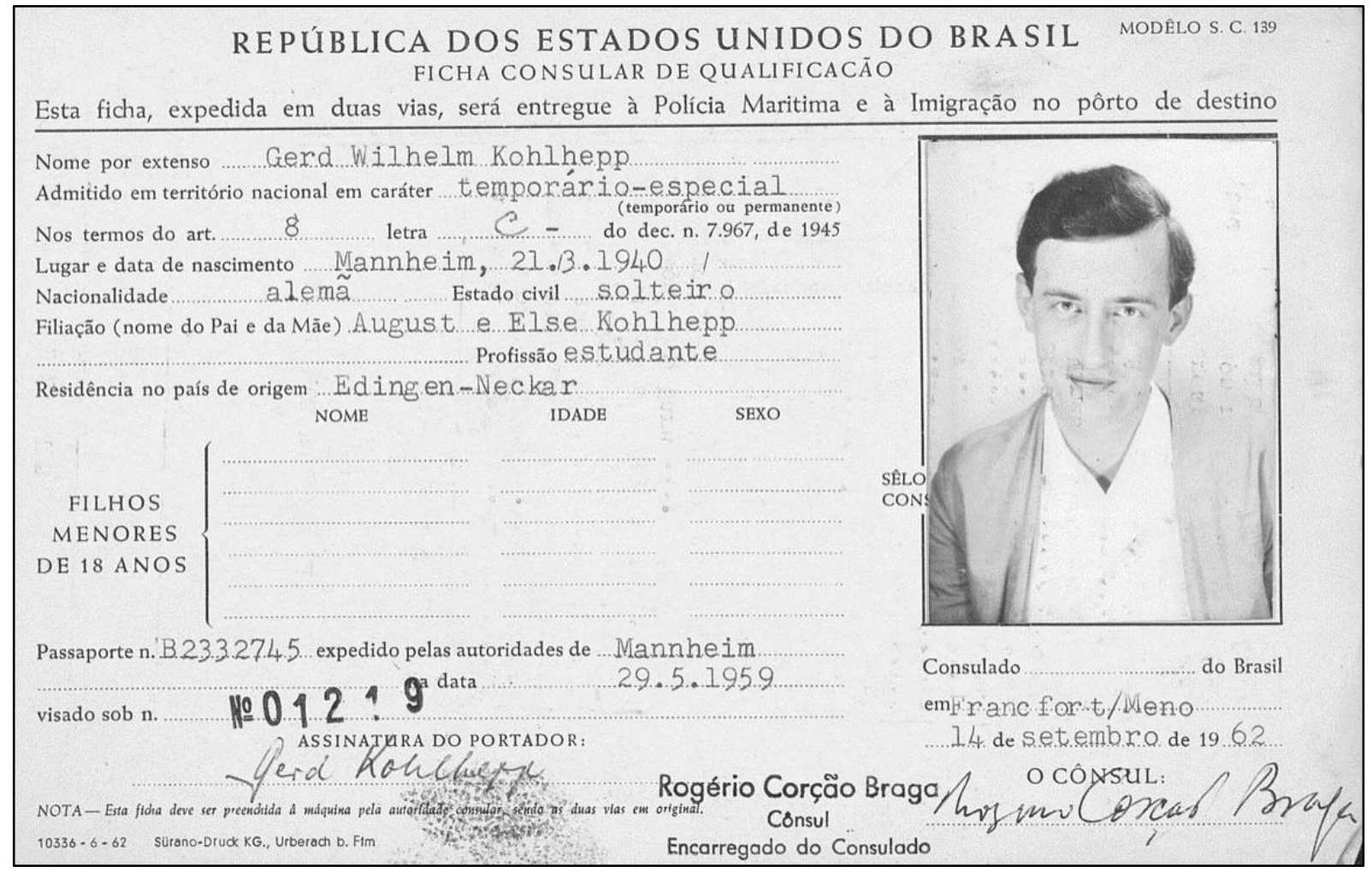

Fonte: Brasil, Cartões de Imigração, 1900-1965." Database with images. FamilySearch. http://FamilySearch.org: 8 April 2020. Arquivo Nacional, Rio de Janeiro (National Archives, Rio de Janeiro).

Kohlhepp tem trabalhado nos últimos anos com temas relacionados ao desenvolvimento regional na Amazônia, a produção de etanol e biodiesel em São Paulo, o significado da indústria para o desenvolvimento do nordeste de Santa Catarina, e uma retomada ao tema clássico da fronteira (frontier). Publicou um número considerável de artigos sobre os fundamentos geográficos sobre o Brasil em coletâneas multidisciplinares e em revistas especializadas. Gerd Kohlhepp atuou como perito em tres grandes programas de pesquisas Alemanha/Brasil: SHIFT (Studies on 
Human Impact on Forests and Floodplains in the Brazilian Tropics: 1993-1998), WAVES (Water Availability of Ecosystems and Society in the Northeast of Brazil: 1996-2001) e CARBIOCIAL (Sequestração de carbono, biodiversidade e estruturas sociais no sul da Amazônia: 2011-2016). Atuou, ainda, em equipe editorial em importantes revistas como a Geographische Zeitschrift e séries de publicações como a Erdkundliches Wissen, Tübinger Beiträge zur Geographischen Lateinamerikaforschung, dentre outras.

\section{PROF. KOHLHEPP, VOCÊ PODERIA FALAR DA SUA RELAÇÃo HISTÓRICA COM A GEOGRAFIA?}

É uma longa história, que eu gostaria de relatar desde o início, quando ainda era aluno de escola primária. Sempre tive uma ligação com a geografia através de sonhos, sonhos esses que faziam me ver a terra de cima como se fosse uma fotografia aérea ou como uma imagem de satélite. Naquele momento eu não tinha explicação para tal e assim, com o auxílio de um atlas mundial, podia ver os países da Europa e do mundo, principalmente os países tropicais - foi o início do meu interesse pela geografia. Depois do período escolar ginasial, iniciei meus estudos em 1958 na Universidade de Heidelberg, a universidade mais antiga da Alemanha, fundada no ano de 1386, mais precisamente na Faculdade de Filosofia, que naquele tempo sediava a geografia. Como não era possível estudar somente geografia para o magistério, optei adicionalmente pela geologia que é de grande significado para a geografia física. Cursei também história e pré-história. Para suporte da geografia econômica cursei ainda economia.

Naquela época o Prof. Gottfried Pfeifer lecionava geografia, sendo que a geografia humana era o seu tema central. Pfeifer especializou-se também em assuntos regionais da América Latina. Em 1950, Pfeifer permaneceu seis meses no Brasil a convite do Prof. Waibel, que trabalhou de 1946 a 1950 como conselheiro científico no Conselho Nacional de Geografia no Rio de Janeiro. Além disso, Pfeifer participou, em 1956, do Congresso de Geografia no Rio, dedicando-se depois, abrangentemente, a pesquisas sobre o Brasil. Em Heidelberg, a geografia tinha ampla orientação com base metodológica fundamentada. No final dos anos de 1950, a Universidade de Heidelberg já era fortemente internacionalizada. Não somente a Universidade, mas também a cidade de Heidelberg era mundialmente conhecida, principalmente pelos turistas 
norte-americanos, já que Heidelberg, depois da segunda guerra mundial, sediava o quartel general das tropas de ocupação americanas na Alemanha. Fora alguns professores estrangeiros, $25 \%$ dos estudantes eram provenientes do exterior e muitos de países não europeus.

Durante meus estudos de geografia decidi que, depois de findado o curso básico na geografia física e humana - o que era de grande importância para a geografia regional - queria me concentrar na geografia econômica. Durante a especialização em geografia regional eu já havia adquirido conhecimentos básicos sobre o Brasil. Meus estudos se alteraram e a especialização em geografia regional tornou-se para mim mais interessante pelo contato com um professor visitante brasileiro do Rio de Janeiro que lecionava no nosso Instituto em Heidelberg no semestre de verão de 1961. Era o Prof.Hilgard O'Reilly Sternberg, Diretor do Centro de Pesquisas de Geografia do Brasil da UFRJ, que também era o vice-presidente da União Geográfica Internacional.

Ele preparava suas aulas em idioma inglês para os estudantes alemães. Como ele havia frequentado a escola alemã no Rio antes da guerra e com isso adquirido conhecimentos básicos do idioma alemão, queria então dar suas aulas em Heidelberg em alemão. Isto foi de grande vantagem para os estudantes. Assim ele me pedia para traduzir os seus textos do inglês para o alemão. Dessa forma surgiu um contato mais estreito com o professor brasileiro. Ele havia se interessado pelos meus objetivos estudantis que estavam orientados para a obtenção da licenciatura para o ensino ginasial. Paralelamente eu havia recebido uma oferta para escrever a minha tese de doutoramento sobre um tema da geografia industrial na Alemanha, mais precisamente sobre as cidades industriais de Mannheim e o polo químico de Ludwigshafen, à beira do Rio Reno. O Prof. Hilgard sugeriu que eu fizesse esta dissertação com trabalhos de campo no Brasil. Esta sugestão mudou completamente meus objetivos. Para viajar para o Brasil eu teria que terminar primeiramente os meus estudos. Entrementes era possível fazer um mestrado na Universidade de Heidelberg, o que era compatível com as disciplinas do meu estudo. Geografia era a minha disciplina principal, seguida da geologia e da pré-história. Meu trabalho de mestrado (M.A.) foi sobre um tema da 
geografia regional da França Ocidental (Marais Poitevin), tendo terminado o trabalho em julho de 1962.

Como eu me interessava especialmente pela geografia das indústrias, área metodologicamente ainda pouco tratada dentro da geografia econômica, o Prof. Hilgard sugeriu que eu fosse como doutorando para o seu Instituto no Rio de Janeiro para fazer a minha tese com base em trabalhos de campo no sul do Brasil. No ano de 1962 não era fácil viajar para o Brasil, pois na época não existiam ainda as possibilidades de hoje em dia como bolsas de estudos. Mas, o Prof. Hilgard conseguiu junto ao Ministério da Cultura do Brasil uma bolsa que pagaria o meu voo ida e volta ao Brasil - com a Panair do Brasil.

É possível que eu tenha sido o primeiro europeu que tivesse conseguido esse tipo de bolsa do Brasil. Da Universidade de Heidelberg eu consegui uma modesta bolsa de estudos que garantiu a minha existência no Brasil. Como eu não tive tempo de aprender português depois do meu exame de mestrado e antes da viagem ao Brasil tive que ter algumas aulas de português no Rio. Em seguida aprendi o idioma pelo learning by doing. Depois de uma estada de seis semanas no Rio, o Prof. Hilgard e seus assistentes organizaram uma excursão para Santa Catarina da qual participou também o Prof. Pfeifer, meu chefe de Heidelberg. Durante esta excursão os dois professores Hilgard e Pfeifer decidiram "deixar-me para trás" em Joinville de forma a iniciar meus trabalhos de campo para a minha tese de doutorado. Para mim, a decisão causou grande surpresa, pois ainda não conhecia ninguém e os professores não tinham contatos diretos em Santa Catarina que pudessem me ajudar. Graças ao jeito sociável e gentil dos brasileiros eu pude desenvolver, em pouco tempo, um círculo de amigos e conhecidos fazendo com que eu me sentisse "em casa" muito rapidamente. 
Prof. KOHLHEPP, ANTES DE DISCUTIRMOS SOBRE A SUA EXPERIÊNCIA COMO UNIVERSITÁRIO ESTRANGEIRO EM PESQUISA NO BRASIL, EU GOSTARIA QUE VOCÊ VOLTASSE UM POUCO CRONOLOGICAMENTE E NOS RELATASSE SOBRE AS REFERÊNCIAS DA GEOGRAFIA ALEMÃ NO SEU TRABALHO. EU SEI LEO WAIBEL E GOTTFRIED PFEIFER FORAM INFLUÊNCIAS MARCANTES, ALÉM, EVIDENTEMENTE, DO PROF. HILGARD STERNBERG, QUE ESTEVE JUNTO COM VOCÊ NESSA SUA PRIMEIRA VIAGEM A SANTA CATARINA. VOCÊ PODERIA DISCORRER SOBRE O CENÁRIO DA GEOGRAFIA ALEMÃ NO PERÍODO DA SUA FORMAÇÃO?

Durante meus estudos eu naturalmente fui apresentado pelo Prof. Pfeifer aos métodos do seu professor nas Universidades de Kiel e Bonn, Leo Waibel. Em 1911, Waibel já havia realizado pesquisas na África tropical expandindo mais tarde seus estudos para as regiões subtropicais do sudoeste da África. Ele foi um dos mais renomados geógrafos alemães, que durante suas pesquisas em geografia econômica no México no final dos anos de 1920 elaborou o conceito da "formação econômica" para a paisagem marcada, de certa forma, pelo homem economicamente ativo. A partir de 1929 ele foi diretor do Instituto Geográfico da Universidade de Bonn que se tornou um dos Institutos mais renomados da Alemanha.

Quando os nazistas assumiram o poder em 1933, começaram suas dificuldades. Ele era casado com uma judia e tinha criticado o sistema político. Depois de negar a infame sugestão do ministério de divorciar-se de sua esposa, foi demitido da Universidade de Bonn em 1937, sendo igualmente proibido de lecionar em universidades alemãs.

Assim, Waibel foi obrigado e conseguiu emigrar em 1939 para os Estados Unidos antes do início da segunda guerra mundial. Depois de atividades científicas nos Estados Unidos -, onde ele teve dificuldades como cidadão alemão na designação para uma cátedra, ele recebeu através de seus doutorandos brasileiros um convite oficial do governo do Brasil para exercer a tarefa de perito do Conselho Nacional de Geografia no Rio de Janeiro. Com satisfação Waibel aceitou o convite em 1946. Nesta função ele ocupou-se com a colonização agrária e com o uso da terra em diversas regiões brasileiras. No final das suas atividades no Rio em 1950 ele convidou seu discípulo Gottfried Pfeifer para realizarem excursões pelo Brasil. Através desta cooperação Waibel-Pfeifer e suas pesquisas, os estudantes em Heidelberg tiveram a oportunidade de conhecer muito sobre o Brasil como o maior país tropical do mundo. 
Assim, também eu fui familiarizado com essa tradição com o Brasil e iniciei minhas pesquisas no Sul e mais tarde em diversas outras regiões do país.

PfEIfER FOI, PORTANTO, UMA GRANDE INFLUÊNCIA NA SUA RELAÇÃo COM A GEOGRAFIA ALEMÃ E COM AS SUAS ESCOLHAS EM TER O BRASIL COMO OBJETO DE INVESTIGAÇÃO. ANTERIORMENTE VOCÊ HAVIA MENCIONADO TAMBÉM HILGARD STERNBERG. COMO FOI ESSA CONEXÃo HILGARDPFEIFER NAS SUAS ESCOLHAS PARA OS ESTUDOS GEOGRÁFICOS NO BRASIL?

Assim pode ser identificada uma linha de pesquisa conduzida por Waibel a Pfeifer, por geógrafos brasileiros como O'Reilly Sternberg e Valverde até a mim e meus colaboradores e estudantes. Enquanto na Alemanha existia uma forte hierarquia entre professores, colaboradores e estudantes, nós aprendemos com o Prof. Hilgard que no Brasil tudo era mais pessoal e que o tratamento dos professores era possível pelo nome, o que na Alemanha até hoje normalmente não é uso. Prof. Pfeifer tinha muito bons conhecimentos teóricos e regionais sobre o Brasil, mas não falava português e comunicava-se com um espanhol misturado com inglês ou mesmo em inglês. Naturalmente foi de grande vantagem para mim no Brasil já conhecer o Prof. Hilgard que tinha inúmeros contatos a todos os níveis no país o que me ajudou na formação de uma rede própria de contatos. Mas, em 1963 ele foi convidado como professor visitante nos Estados Unidos pela University of California em Berkeley sendo professor de Geografia da América Latina e onde ficou - infelizmente para mim - até o fim da sua carreira. Muitas vezes tive a oportunidade de visitá-lo em Berkeley e mesmo de lá trabalhar como professor visitante durante algumas semanas em 1985.

COMO FOI A SUA RELAÇÃO COM AS UNIVERSIDADES E INSTITUIÇÕES BRASILEIRAS NA ÉPOCA DA SUA PESQUISA? E A SUA RELAÇÃO COM OS GEÓGRAFOS BRASILEIROS? QUERO DIZER, ALÉM DE

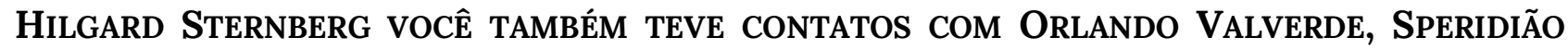
FAISSOL DENTRE OUTROS PESQUISADORES DO IBGE. COMO FORAM ESSAS EXPERIÊNCIAS?

Durante a minha primeira estada no Brasil, iniciei como doutorando em 1962 no Centro de Pesquisas de Geografia do Brasil no Rio de Janeiro. O Prof. Hilgard era diretor e a sua primeira assistente foi a Profa. Maria do Carmo Corrêa Galvão. Ela é paulista, mas já estava bem aclimatizada no Rio. Como primeira brasileira, ela havia feito seu doutorado sobre um tema da geografia regional na Alemanha com o Prof. 
Carl Troll em Bonn. Com isso ela teve a oportunidade de aprender muito bem o idioma alemão. Foi ela quem muito me ajudou no meu início no Instituto. Além da Profa. Maria do Carmo, lá encontrei a Bertha K. Becker que mais tarde tornou-se muito conhecida no Brasil pelas suas pesquisas sobre a Amazônia. Ela também foi assistente do Prof. Hilgard. No Centro de Pesquisas havia um ambiente muito simpático. Eu tinha um relacionamento muito bom com os assistentes e outros doutorandos, entre outros como Lia Osório Machado, o que perdura até hoje. Como estrangeiro não me senti como um estranho no Instituto, embora no início eu ainda não falasse bem o português e assim nós nos comunicávamos em inglês. Mas logo pudemos falar português devido à melhora dos meus conhecimentos do idioma.

De grande significado foi então o contato com Orlando Valverde do Conselho Nacional de Geografia. Valverde foi um colaborador de Waibel quando este trabalhou no Rio. Valverde tinha muitos contatos internacionais e pelo estreito trabalho com Waibel, ele aprendeu um pouco o alemão como também a metodologia da geografia alemã - e foi decisivo na introdução dessa metodologia no Brasil. Antigamente, a geografia brasileira era totalmente influenciada pelos geógrafos franceses. O Prof. Valverde era um cientista extremamente extrovertido - um especialista em geografia agrária que se ocupava muito intensamente com geógrafos estrangeiros que visitavam o CNG. Depois que o Prof. Hilgard emigrou para os Estados Unidos em 1963, Valverde e os colegas da UFRJ tornaram-se para mim a primeira instância geográfica em muitas pesquisas no Brasil. O seu grande interesse pela pesquisa sobre a Amazônia trouxe grande conexão entre nós. Em 1967 ele foi professor visitante no meu antigo Instituto na Universidade de Heidelberg. Através de Orlando eu conheci uma série de colegas, entre outros, Nilo Bernardes, Lysia Maria Cavalcanti Bernardes, Speridião Faissol, Pedro Geiger, Irene Garrido Filha e muitos outros. Duas jovens colegas no CNG também passaram um tempo com bolsas de estudos na Universidade de Heidelberg.

Assim dois grupos de colegas no Rio de Janeiro foram de grande importância para mim, com os quais eu sempre mantive estreito contato científico e amizade pessoal. Este foi o grupo do Prof. Hilgard no Centro de Pesquisas de Geografia do Brasil e do outro lado havia o grupo do CNG com Orlando Valverde, sendo que se podia verificar certa competição científica entre os dois grupos. A amizade com 
Hilgard, Orlando, Carmo e Bertha permaneceram durante mais de 40 anos - eles "abriram" o Brasil para mim deixando uma profunda impressão científica e pessoal.

VOCÊ MENCIONOU A INFLUÊNCIA DA GEOGRAFIA FRANCESA NO SURGIMENTO E MESMO NA CONSTRUÇÃO DA GEOGRAFIA BRASILEIRA. ELA DESENVOLVE-SE COM MAIS PESO, SE POSSO ASSIM DIZER, NA UNIVERSIDADE DE SÃo PAUlo. EXISTE UMA ESTÓRIA DE QUE HAVIA CERTO CONFLITO ENTRE A ESCOLA NORTE-AMERICANA E ALEMÃ NA UNIVERSIDADE FEDERAL DO RIO DE JANEIRO E a influÊnCia francesa na Universidade de SÃo Paulo. VocÊ Chegou a Perceber a EXISTÊNCIA DESSE CONFLITO NOS DEPARTAMENTOS DE GEOGRAFIA NO BRASIL?

Esta é uma pergunta interessante, pois como estrangeiro observa-se não somente o trabalho científico, mas também os respectivos contatos dos colegas dentro do próprio país. Assim percebia-se nos anos 1960 que o Instituto no Rio não convidava colegas de São Paulo para palestras e vice-versa os cariocas também não recebiam convites dos paulistas. Assim eu não tinha, durante muito tempo, contato direto com a geografia do Instituto na USP. Numa das minhas viagens posteriores, visitei os colegas geógrafos da USP apresentando também o meu trabalho. Ficou claro que antigamente havia certa concorrência direta e indireta entre as metrópoles São Paulo e Rio como também entre os Institutos de geografia das respectivas Universidades, pressupostamente devido às diferentes "escolas" geográficas. Em São Paulo, nos anos de 1930, renomados geógrafos franceses já estavam envolvidos na fundação da USP influenciando fortemente os colegas de São Paulo. Através de bolsas de estudos francesas para doutorandos brasileiros esta tradição foi aprofundada. A metodologia americana e alemã concentrava-se mais no Rio. Nos anos seguintes eu tive a oportunidade de fazer amizade com o grande geógrafo da USP, Aziz Nacib Ab'Saber, que era internacionalmente conhecido na geomorfologia e grande conhecedor da Amazônia.

VOCÊ PODERIa APROVEITAR E FALAR UM POUCO SObRe a SUA RELAÇÃo COM AZIZ NACIB AB'SABER? OS TRABALHOS DE AB'SABER SÃo HOJE UMA GRANDE REFERÊNCIA PARA OS ESTUDOS AMBIENTAIS, SOBRETUDO PELA TEORIA DOS DOMÍNIOS MORFOCLIMÁTICOS.

Aziz foi uma grande personalidade na geografia física no Brasil. Ele não tinha somente um profundo conhecimento geográfico, mas desempenhava papel 
internacional destacado na geomorfologia, na climamorfologia, etc. Primeiramente tínhamos contato através de publicações e não tínhamos projetos comuns devido às diferentes ênfases dentro da geografia. Mais tarde e através de pesquisas sobre o meio ambiente e pesquisas sobre problemas da geografia regional da Amazônia, tivemos maior contato. Em congressos e mesmo em sua casa tivemos interessantes debates, sobretudo sobre questões do desenvolvimento regional na Amazônia. Seu profundo conhecimento era impressionante. Também na implantação política de resultados científicos sobre o meio ambiente ele alcançou grande renome. Durante o Congresso de Americanistas em Estocolmo em 1993 nós coordenamos uma sessão juntos. Ele sempre me convidou a publicar trabalhos na Revista de Estudos Avançados da USP. Suas atividades científicas perduraram até idade avançada.

VocÊ DISSE QUe a SUA PESQUiSa GEOGRÁfica No BRASIL TEVE COMO TEMA INICIAL O SEU TRABALHO SOBRE A INDUSTRIALIZAÇÃo NO NORDESTE DE SANTA CATARINA. MAS DEPOIS VOCÊ FEZ UMA MUDANÇA DE TRAJETÓRIA, DEIXANDO OS ESTUDOS SOBRE INDUSTRIALIZAÇÃO E VOLTANDO-SE PARA OS ESTUDOS MAIS RELACIONADOS AO MUNDO RURAL, A EXPANSÃO DA FRONTEIRA E AOS PROCESSOS DE COLONIZAÇÃO, SOBRETUDO NO NORTE DO PARANÁ E TAMBÉM NA AMAZÔNIA. COMO SE DEU ESSA MUDANÇA?

Durante o tempo do meu doutoramento, a geografia das indústrias ainda era um ramo negligenciado na geografia econômica e com isso na geografia humana. Enquanto antigamente a maioria das pesquisas se ocupava com temas da geografia urbana e planejamento urbano, eu achei importante trabalhar em outros campos de pesquisa como a geografia econômica, pois era de especial significado para o desenvolvimento regional. Até então, esta temática era desenvolvida somente por economistas. Assim decidi trabalhar, também no Brasil - em Santa Catarina considerando, sobretudo as pequenas e médias indústrias que haviam surgido de capital local. Antigamente existiam somente poucas indústrias maiores. Muito interessante era a ligação da origem dos empresários com a imigração alemã e italiana, que era significante no Nordeste de Santa Catarina. A qualidade da mão-deobra era especialmente apreciada no Brasil. Em Santa Catarina este fato era ligado à tradição da imigração europeia, pois na Alemanha ou na Itália a formação dos trabalhadores nos mais diversos níveis tinha cada vez mais significado. Através disso 
eram adquiridos conhecimentos especiais na produção em Santa Catarina como, por exemplo, na construção de máquinas como na indústria têxtil e de vestuário etc. Isto sempre me impressionou, considerando os mais diversos ramos da indústria, pois não era comum nas outras regiões do Brasil.

Em Santa Catarina concentrei meus trabalhos ao Nordeste desse Estado, fortemente industrializado já que eu não tinha tanto tempo à disposição para estudar todo o Estado. Assim iniciei as entrevistas no planalto de Mafra, na fronteira com o Paraná, e em São Bento, seguido de Joinville, Jaraguá do Sul e finalmente Blumenau e toda a região do Rio Itajaí-Açu como também o Itajaí-Mirim com Brusque. Para citar somente um exemplo do desenvolvimento: Em 1963, em Jaraguá do Sul, fiz uma entrevista com um historiador local que me explicou o desenvolvimento da cidade e a colonização em seus arredores. Um dia ele me levou a uma oficina pequena, do seu filho, que com mais três trabalhadores ocupavam-se da montagem de motores elétricos. Como antigamente havia uma situação econômica muito difícil, fiquei preocupado com o futuro desta pequena empresa. 25 anos mais tarde visitei novamente Jaraguá do Sul e entrevistei o filho e neto do fundador da empresa. Entrementes aquela pequena empresa havia se constituído um grupo de empresas de renome internacional com 11 filiais nos mais diversos países e com 18.000 funcionários. É a empresa WEG S.A., um modelo exemplar de desenvolvimento positivo, com instalações sociais, assistência médica e instalações de lazer para funcionários - tudo isso me deixou muito impressionado. Eu poderia citar ainda diversos exemplos em Santa Catarina que muito se desenvolveram de 1960 a 1990. Nestas entrevistas, no âmbito do meu doutoramento, tive contato com todas as camadas sociais. Estudei minuciosamente as condições de trabalho e o alto nível da qualidade de produção para o mercado brasileiro das diversas empresas de todos os ramos.

Referente à sua pergunta sobre o desenvolvimento das minhas pesquisas no Brasil: depois que me ocupei metodologicamente com a geografia das indústrias, queria então seguir meus trabalhos na área da geografia agrária. No ano de 1963, no final dos meus trabalhos de campo para a tese de doutorado fiz uma excursão de Santa Catarina ao Norte do Paraná. De Curitiba até o Oeste as estradas não eram 
asfaltadas e em Guarapuava eu presenciei o inverno sul-brasileiro de $4^{\circ} \mathrm{C}$ negativos no mês de agosto e muita lama até Foz do Iguaçu com suas cataratas maravilhosas. A viagem ao longo do Rio Paraná foi impressionante pela passagem por matas tropicais até os Saltos de Guaíra, seguindo para Maringá e Londrina. A dinâmica da economia e o avanço da fronteira na região do Norte do Paraná, marcada pelo café me entusiasmaram de tal forma que eu resolvi fazer meu trabalho de pós-doutoramento sobre a geografia agrária e o desenvolvimento dessa região. Na Alemanha, este nível da carreira universitária é chamado de Habilitation - livre docência.

Figura 02. A foto mostra uma escola em construção na antiga frente pioneira nas florestas tropicais no oeste de Umuarama, Paraná. Naquele momento as mesas e bancos da escola estavam sendo entregues. As crianças, eram filhos de famílias migrantes oriundas de Minas Gerais, Nordeste e do Sul do Brasil. Esta era uma região de encontro de duas correntes migratórias. A foto foi tirada durante uma excursão feita por Kohlhepp em 1963 (em pé, e de óculos escuros), partindo de Santa Catarina para o Norte do Paraná. O motorista (sem identificação) foi o fotógrafo.

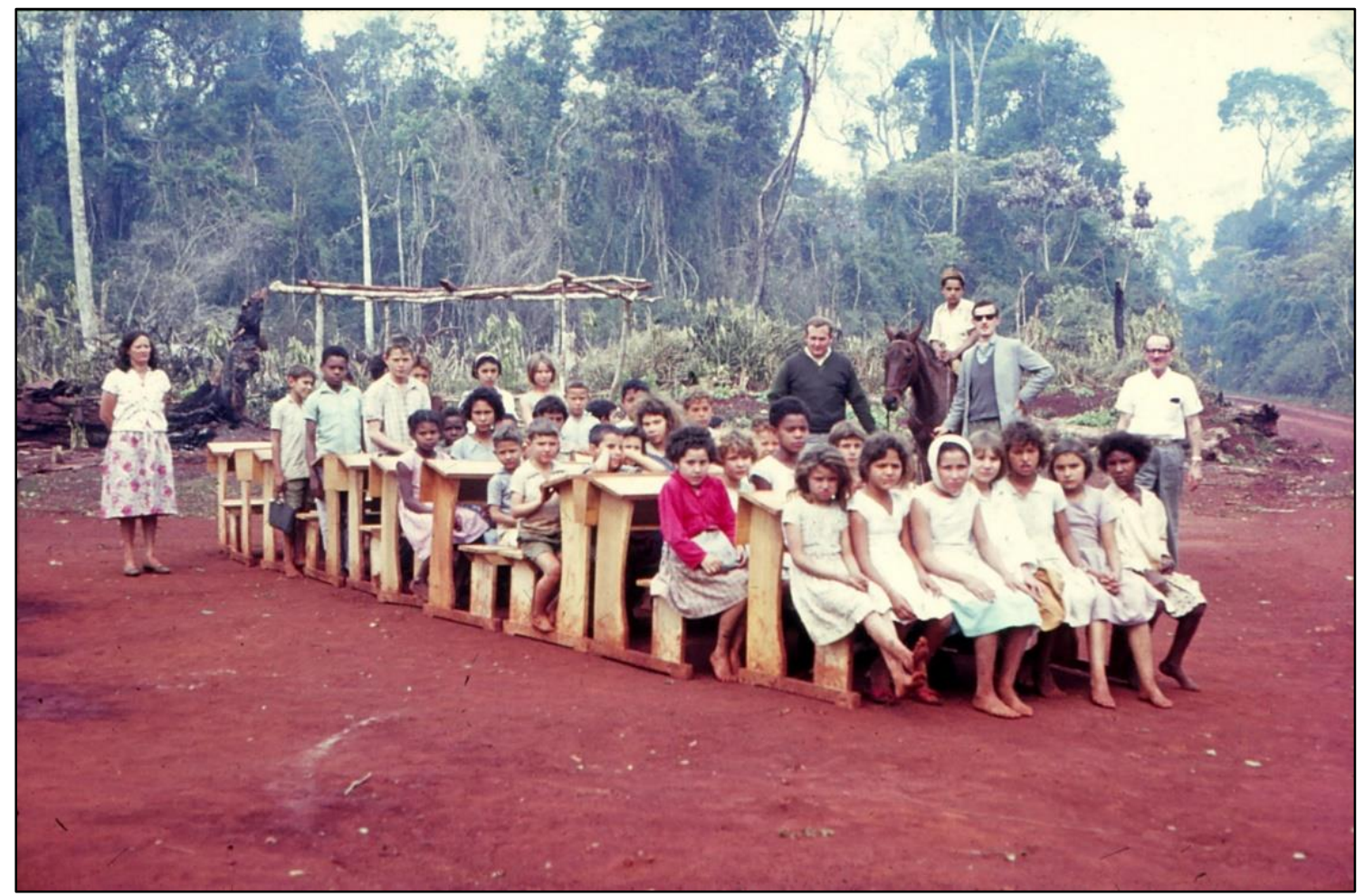

Fonte: Arquivo pessoal de Gerd Kohlhepp.

No ano de 1970 e com apoio financeiro do CNPq alemão (DFG) iniciei meu projeto de pesquisas no Norte do Paraná, lá permanecendo por quase um ano. Depois de realizar centenas de entrevistas com pessoas das mais diversas classes sociais pude conseguir uma imagem detalhada dessa região de plantação do café, antigamente a maior do mundo que, depois de fortes geadas que provocaram grandes danos, passou 
por mudança radical. Assim, a plantação da soja começou a se espalhar pelo Norte do Paraná como também a pecuária.

Como eu ainda vivenciei a produção do café, eu tinha o costume de tomar uma série de cafezinhos quando visitava as empresas. Meu estômago não se acostumou a tanto café, tornando-me assim um fiel consumidor de chá, mas com ligação emocional à antiga plantação do café no Paraná. O Norte do Paraná me fascinou pela rápida mudança da economia agrícola. Paralelamente pude ver a destruição das últimas matas tropicais no Norte do Paraná por desmatamento de enormes áreas.

Quando relato sobre o Paraná, não posso deixar de mencionar especialmente uma pessoa: Reinhard Maack ${ }^{9}$ - um imigrante alemão dos anos de 1920. Ele foi um grande pesquisador, geólogo e geógrafo que além de produzir excelentes mapas para a geologia e vegetação do Paraná, publicou também um livro sobre a geografia física daquele estado, normativa até os dias de hoje. Ele muito me ajudou nos primeiros contatos no Paraná, podendo mais tarde estendê-los.

Durante o Governo Militar o trabalho com mapas era difícil, ainda mais porque geógrafos também trabalham com fotografias aéreas. Outro problema que se apresentava era a fronteira com outro país, isto é, com o Paraguai. E de acordo com a legislação brasileira, não era permitido a estrangeiros realizar pesquisas num território a $150 \mathrm{~km}$ da fronteira, especialmente em estado de emergência política. Eu havia recebido um documento oficial do Ministério do Interior para poder realizar esse trabalho, mas infelizmente a polícia regional não aceitou o meu documento fazendo com que eu tivesse que permanecer dias no hotel até que o caso fosse esclarecido. Com a ajuda da UFRJ o caso foi finalmente resolvido. 
ATUALMENTE O USO DO GIS É FREQUENTE PARA ESTUDOS DA GEOGRAFIA FÍSICA E ATÉ MESMO DE

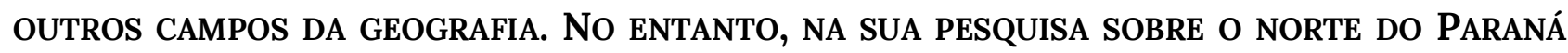
VOCÊ PRECISOU ELABORAR OS SEUS PRÓPRIOS MAPAS COM BASE EM FOTOGRAFIAS AÉREAS. E UMA DAS COISAS QUE MAIS ME DESPERTOU A ATENÇÃO EM SUA PESQUISA SOBRE O NORTE DO PARANÁ FOI A RIQUEZA E A BELEZA DO MATERIAL CARTOGRÁFICO E DOS MAPAS QUE VOCÊ MESMO ELABOROU PARA AQUELE TRABALHO. VOCÊ PODERIA EXPLICAR UM POUCO PARA NÓS COMO QUE ESSE PROCESSO DE PRODUÇÃO DESSES MAPAS OCORREU?

Pois bem, como geógrafo com formação tradicional eu havia aprendido a fazer mapas, mapas esses com base em medições, com diferentes escalas e com diferenciações de cores na legenda etc. Além disso, eu tinha que naturalmente fazer gráficos para a apresentação de valores estatísticos. Mas, o mais importante eram as fotografias aéreas para o mapeamento do uso da terra. Era muito difícil conseguir estas fotografias, além de serem muito caras. Neste caso tive novamente a ajuda de gentis brasileiros, funcionários de repartições públicas. Infelizmente as fotografias aéreas mais recentes não podiam ser vendidas para estrangeiros de forma que tive que me contentar com as mais antigas. Assim fui obrigado a fazer o mapeamento eu mesmo, tomando como base fotografias de 1955 e próprias para a atualização até o ano de 1970, como por exemplo, os dados de uma empresa agrícola. Tudo foi realmente muito trabalhoso e "a pé". Na Alemanha e com base nesse material, os mapas tinham que ser trabalhados com cores e desenhados em papel transparente para publicação. Isto decorreu em trabalho próprio sem ajuda de cartógrafos do Instituto, pois só podiam trabalhar para professores. Para a impressão era necessário fazer novos padrões a cores e investir muito trabalho. Dessa forma foram feitos muitos mapas, constantes do meu livro sobre a "Colonização agrária no Norte do Paraná. Processos geoeconômicos e sociogeográficos de desenvolvimento de uma zona pioneira no limite da zona tropical do Brasil sob a influência da plantação do café"10.

Nisso ainda um detalhe: naturalmente eu queria que essa tese de livre docência fosse paralelamente publicada para o português. Uma tradução do trabalho, caríssima na Alemanha, estava fora de cogitação no meu país. Algumas negociações com o IBGE previam uma tradução no Brasil e até o financiamento estava garantido,

10 Gerd Kohlhepp, Colonização Agrária No Norte Do Paraná: Processos Geoeconômicos e Sociogeográficos de Desenvolvimento de Uma Zona Subtropical Do Brasil Sob a Influência Da Plantação de Café (EDUEM, 2014), https://doi.org/10.7476/9788576286554. 
mas, na última hora, devido à troca da diretoria daquela Instituição, não mais foi possível levar o projeto da tradução adiante. Lamentei muito justamente porque o trabalho em alemão não estaria à disposição de muitos colegas e para um maior público de leitores no Brasil. Por iniciativa de um professor brasileiro de Letras, especialista em alemão, Paulo Astor Soethe, e seu time da Universidade de Curitiba (UFPR) deu-se, 42 anos mais tarde, uma chance de tradução para o português do livro sobre a geografia agrária no Norte do Paraná com ajuda de financiamento pela Fundação Araucária no Paraná junto com uma Fundação em Baden-Württemberg na Alemanha. A editora da Universidade Estadual de Maringá publicou o trabalho com muitos mapas a cores num volume muito bonito em 2.000 exemplares que puderam ser distribuídos gratuitamente. A apresentação do livro em Maringá foi para mim muito impressionante pois a maioria dos presentes eram imigrantes e mais jovens do que os meus trabalhos de campo para a tese, ficando surpreendidos pela antiga estrutura social e agrária de sua região.

De todos os trabalhos posteriores sobre o Brasil realizados por meus doutorandos no Instituto na Universidade de Tübingen foram publicados resumos de 30 páginas em idioma português para os leitores brasileiros. Muitos dos meus trabalhos menores com temas brasileiros foram publicados não somente em idioma português, mas também em revistas especializadas no Brasil. Isto também se refere aos meus trabalhos sobre a Amazônia.

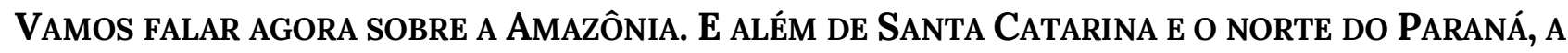
AMAZÔNIA FOI UMA DAS ÁREAS PRIVILEGIADAS NOS SEUS ESTUDOS. QUAL A SUA RELAÇÃo CIENTÍFICA COM A AMAZÔNIA BRASILEIRA, MAS TAMBÉM PARA ALÉM DAS FRONTEIRAS DO BRASIL? E COM QUEM VOCÊ DIALOGOU, TAMBÉM, NESTE PERÍODO?

Primeiramente vou me concentrar na Amazônia brasileira. Tudo começou em 1967 quando Orlando Valverde, do CNG, foi para o nosso Instituto na Universidade de Heidelberg como professor visitante. Pfeifer, Orlando, mais dois colegas alemães e eu discutimos sobre temas para um projeto de pesquisas dentro da geografia humana e em diversas regiões da Amazônia - o que deveria ser realizado por colaboradores do CNG do Rio e de Heidelberg. 
Essa ideia, surgida em 1967, foi apresentada por Orlando Valverde à diretoria do IBGE em 1970, durante os meus trabalhos no Paraná. O objetivo de Orlando era a construção de um barco para os trabalhos na Amazônia, que deveria levar o nome do conhecido geógrafo alemão Leo Waibel. Antigamente ainda não existiam estradas na Amazônia, sendo construídas somente a partir de 1973. Nós havíamos combinado que o lado alemão arcaria com os custos do motor e aparelhagem e o lado brasileiro se ocuparia da construção do barco e tudo que estivesse relacionado à equipe.

O financiamento pelo lado alemão foi rapidamente esclarecido. As dificuldades para a concessão de meios pelo lado brasileiro (leia-se IBGE e Governo Militar) foram subestimadas por Orlando. Nesta fase era difícil realizar pesquisas na Amazônia em cooperação com estrangeiros. O problema surgiu depois que geólogos americanos realizaram uma expedição no Rio Amazonas sem informar anteriormente o Governo Brasileiro - segundo nota dos órgãos oficiais. O nosso projeto havia sido admitido no acordo científico Alemanha-Brasil de 1973, o que deveria impulsionar especialmente a pesquisa bilateral. Como o Conselho Nacional de Geografia era uma instituição do governo, dependia de decisões de Brasília. Neste tempo, a diretoria do CNG mudou duas vezes e como havia certo clima de concorrência interna entre os cientistas o projeto foi recusado, justificado por dificuldades financeiras e administrativas pelo lado brasileiro. Isto significou que os meios financeiros concedidos pela Alemanha tiveram que ser devolvidos. Um caso incomum, mas que no final tornou-se positivo para mim pois os meios puderam ser usados para a minha própria pesquisa infelizmente sem construção de barco. Entrementes a construção de estradas na Amazônia permitia o acesso a algumas regiões e pequenos projetos puderam ser realizados. Estes projetos faziam parte então da minha própria pesquisa e não faziam parte de cooperação direta, no entanto, mantive constante contato com Orlando e seus colaboradores. Mais tarde foram realizados novos projetos com pesquisadores alemães e brasileiros.

Assim foi iniciada a minha pesquisa no ano de 1973 sobre a colonização agrária na Transamazônica entre Altamira e Itaituba. Não obstante, a realização do planejamento no local, a despeito das difíceis condições de logística, foi interessante. O estabelecimento de colonos, primeiramente do Nordeste, depois do Sudeste e do 
Sul do Brasil mostrou-se problemático, pois as condições ecológicas na mata tropical úmida não lhes eram familiares. Muitas entrevistas eram feitas nas agrovilas e nos lotes dos colonos. Aos poucos se formou uma comunidade de pesquisadores brasileiros e colegas estrangeiros que se ocuparam com o desenvolvimento regional na Amazônia. Alguns dos meus trabalhos seguintes trataram de projetos sobre a problemática ecológica da pecuária na Amazônia, projetos de hidrelétrica (Tucuruí) e programas de desenvolvimento regional (entre outra Grande Carajás) com grande impacto humano por devastação das florestas tropicais.

Pouco antes da conferência ECO-92 no Rio de Janeiro, os países do G7 por iniciativa alemã sugeriram ao Governo Brasileiro criar um programa de proteção ao meio ambiente para ajudar na realização do desenvolvimento regional sustentável e evitar também a devastação da floresta na Amazônia. O Governo Brasileiro aceitou esta proposta. Os países do G7 financiaram este Programa com doações não reembolsáveis. As doações, no valor de 450 milhões de dólares - sendo a participação da Alemanha de 45\%. Este foi o primeiro Programa Internacional de Proteção ao Meio Ambiente para as Florestas Tropicais e, em minha opinião, foi e é até os dias de hoje, o melhor Programa. Assim foi conseguida a descentralização da política do meio ambiente passando para os níveis regional e comunal. Foram principalmente apoiados os pequenos projetos da população local. Um projeto importante foi à demarcação de territórios indígenas e a proteção dos grupos indígenas. Estes desenvolvimentos foram especialmente considerados nas minhas pesquisas.

\section{QUAL ERA O NOME DESSE PROJETO?}

Este programa de meio ambiente, que perdurou de 1993 até 2008, foi chamado de "Programa Piloto Internacional para a Proteção das Florestas Tropicais do Brasil". Era também conhecido como PPG7, isso porque o programa recebia financiamento internacional dos países do G7. O Programa foi elaborado principalmente para a região Amazônica, dedicando-se, no entanto, também a partes de projetos na Mata Atlântica. O Banco Mundial tinha somente a incumbência da coordenação e não intervinha nas decisões do Governo Brasileiro. Foi nomeada uma comissão internacional de peritos científicos (International Advisory Group - IAG), fazendo 
parte do grupo 11 cientistas das mais diferentes disciplinas e oriundos de 7 países, com grande experiência em pesquisas na Amazônia. Eu tive a honra de ser chairman deste grupo por quatro anos, ficando nove anos como membro da Comissão.

Quais eram as tarefas desse grupo científico? Tínhamos que acompanhar minuciosamente o Programa PPG7 e julgar os projetos instalados apresentando sugestões de melhoras e ponderações aos envolvidos do Governo Brasileiro. Para tal eram realizadas excursões diversas vezes ao ano a diferentes partes da região Amazônica onde projetos já estavam sendo levados adiante - e com interrogatório aos envolvidos no projeto. Os relatórios da IAG eram apresentados aos respectivos Ministérios do Governo Brasileiro, aos países do G7 e ao Banco Mundial. Sugestões e pontos críticos da IAG eram discutidos e considerados em planejamentos futuros e apresentados aos colaboradores para o apoio técnico dos projetos. Naturalmente este projeto também apresentava deficiências, pois nem todos os Ministérios tinham participação e nem todas as sugestões puderam ser realizadas. Ao todo, pode se dizer que o PPG7 foi o programa de meio ambiente em regiões de florestas tropicais mais bem-sucedido. Infelizmente não se podia conseguir reduzir mais fortemente a devastação das florestas. Em todo caso uns conjuntos de empreendimentos foram muito importantes: a inovação com miniprojetos com exemplo na agrossilvicultura; o envolvimento da população local, dos ribeirinhos e da população indígena; a formação de uma política regional própria dos Estados da Amazônia; os diálogos entre os envolvidos, agentes estatais e privados; a colaboração de ONGs brasileiras, muito ativas e que muito haviam feito para a proteção do meio ambiente na Amazônia. Tudo isso foi muito importante para as minhas pesquisas, pois pude ter uma boa visão da política estatal para o meio ambiente.

Em meados de 1970 ainda era muito difícil viajar pela Amazônia. Deu-se uma nova situação que me pegou de surpresa: em Belém, fui apresentado ao Comandante General da Força Aérea ${ }^{11}$ para a Amazônia pelo Vice-Reitor da Universidade Federal do Pará (UFPA), Prof. Antônio Vizeu da Costa Lima, que sempre muito me ajudou. O General era fã de geografia e conhecia a crítica internacional sobre a exploração da Amazônia. A seu convite, mesmo sendo cientista estrangeiro, visitei territórios

11 O entrevistado não mencionou o nome, mas provavelmente ele estivesse se referindo ao Brigadeiro João Camarão Telles Ribeiro (1916-2000) 
indígenas muito afastados que eram abastecidos pela Força Aérea. Além disso, pude visitar regiões que eu nunca teria podido visitar - especialmente como pesquisador estrangeiro.

Os programas de pesquisas bilaterais entre o Brasil e a Alemanha tinham, desde os anos de 1990, grande significado. Aqui quero mencionar o Programa SHIFT (Studies on Human Impact on Forests and Floodplains in the Brazilian Tropics), que com inúmeros projetos e a participação de universidades dos dois países, puderam alcançar ótimos resultados. Depois desses trabalhos, muitos cientistas obtiveram bons cargos em universidades no Brasil e na Alemanha. De Tübingen eu coordenei um grande projeto multidisciplinar em Mato Grosso, na região do Alto Paraguai e do Pantanal. Nosso parceiro foi a UFMT em Cuiabá. 25 cientistas, sendo 15 brasileiros e 10 alemães, participaram do projeto. O trabalho que durou quase 10 anos resultou em conhecimentos detalhados sobre imigração, reorganização e modernização da economia agrícola, desenvolvimento urbano, planejamento regional, estabelecimento de áreas de proteção à natureza etc. Mais tarde fui perito em outros programas bilaterais de pesquisas Brasil-Alemanha ${ }^{12}$.

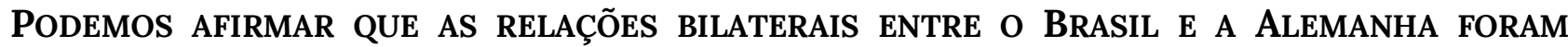 IMPORTANTES PARA O DESENVOLVIMENTO DE PESQUISAS SOBRE OS TRÓPICOS, FAVORECENDO UM PRODUTIVO INTERCÂMBIO ENTRE PESQUISADORES DOS DOIS PAÍSES. COMO SE ESTABELECEU ESSA RELAÇÃO BILATERAL EM TÜBINGEN? COMO ELA SE ORGANIZOU E SE INSTITUCIONALIZOU?}

Quero responder resumidamente. Depois de defender a minha tese de livre docência em Heidelberg em 1972, eu fui nomeado no mesmo ano para exercer a função de professor titular de geografia humana na Universidade de Frankfurt/Main. Em 1978 foi nomeado pela Universidade de Tübingen, uma das mais antigas da Alemanha - fundada em 1477 -, para a cátedra de geografia econômica e social. Uma curta explicação: Na Alemanha não é possível vir a ser professor na mesma universidade na qual se passou a fase de estudos, doutoramento, pós-doutoramento e livre docência. É necessária a transferência para outra universidade. Nisso há um concurso cujo final deve ser exitoso. Eu tive que prestá-lo em Frankfurt e em

12 WAVES: Water Availability, Vulnerability of Ecosystems and Society in the Northeast of Brazil, 1996-2001; e CARBIOCIAL: Carbon sequestration, biodiversity and social structures in Southern Amazonia, 2011-2016 
Tübingen. Depois de 1978 eu tive a oportunidade de formar, na Universidade de Tübingen, um Centro de Pesquisas de Geografia da América Latina com um curso denominado de "países em desenvolvimento". Para os candidatos desse curso eram realizadas anualmente excursões e trabalhos de campo no Brasil e em outros países latino-americanos, com Argentina, Bolívia e Cuba. Mas, o nosso foco regional na América Latina era o Brasil. Sempre foi possível o intercâmbio de professores e doutorandos com o Brasil.

No ano de 1987 conseguimos iniciar um intercâmbio estudantil com o Departamento de Geografia da UFRJ que seguiu até o ano de 2005 quando me tornei professor emérito. Este intercâmbio era financiado pelo DAAD - Serviço de Intercâmbio Acadêmico Alemão. Este foi o maior intercâmbio de geografia feito pelo DAAD. Os alemães que recebiam bolsa de estudos para o Brasil cediam voluntariamente uma parte da bolsa para os brasileiros, pois a CAPES ainda não financiava o intercâmbio de estudantes. Adicionalmente nós tentávamos conseguir meios financeiros de empresas etc. Assim estudantes brasileiros de geografia podiam estudar em Tübingen. Mais tarde a CAPES passou a pagar bolsas de estudos. No decorrer dos anos eu pude mandar mais de 70 estudantes alemães para o Rio que lá permaneciam por um ano e até mesmo iniciavam seus trabalhos de campo para suas teses de mestrado - além de aprenderem o idioma português. Mais de 40 estudantes brasileiros participaram do intercâmbio e frequentaram o nosso Instituto. Os candidatos a bolsas de estudos tinham que iniciar o aprendizado do respectivo idioma antes do início do programa. Esta cooperação teve também consequências agradáveis: tivemos uma dúzia de casamentos entre estudantes ou doutorandos dos dois países.

Devido aos conhecimentos da língua portuguesa e conhecimentos sobre o país pelos nossos estudantes, eu podia levá-los ao Brasil em projetos de pesquisa e como doutorandos. Alguns dos nossos doutorandos brasileiros tornaram-se mais tarde professores de geografia em universidades brasileiras - dentre estes Marcelo Lopez de Souza (UFRJ) - e alguns dos doutorandos alemães assumiram a posição de professores em universidades na Alemanha, no Brasil e em outros países ${ }^{13}$.

\footnotetext{
13 Para mais informação ver: Gerd Kohlhepp, "Nas Trilhas de Leo Waibel: Pesquisas Alemãs de Geografia Humana Do Brasil - de Heidelberg a Tübingen (1950-2005)," Revista Brasileira de Geografia 62, no. 2 (2018): 7-24, https://doi.org/10.21579/issn.2526-0375_2017_n2_p7-24; Gerd
} 
POR FAVOR, KOHLHEPP, TAMBÉM MUITO RAPIDAMENTE, FALE SOBRE A SUA EXPERIÊNCIA NO Conselho de Pesquisa alemão, QuANdo COMEÇOU E COMO ISSO FAVORECEU, TAMBÉm, AS PESQUISAS BILATERAIS COM TEMAS SOBRE O BRASIL?

Na Alemanha temos um modelo semelhante ao Conselho Nacional de Desenvolvimento Científico e Tecnológico (CNPq), que é a Deutsche Forschungsgemeinschaft (DFG). Os projetos de pesquisa são apresentados e cada disciplina científica é avaliada por peritos (professores) segundo severos critérios científicos. Se aceito, o projeto é financiado pelo DFG. Nos anos de 1980 até 1988 fui eleito perito para toda a geografia humana e de 1988 a 1992 era encarregado dos projetos multidisciplinares em países em desenvolvimento. As atividades de avaliação para o DFG corriam paralelamente à minha atividade principal e eram muito trabalhosas.

Muito obrigado Dr. KoHlHepp. EU LHE AGRAdeÇO POR NOS CONCEDER A HONRA DESTA ENTREVISTA. E, EU GOSTARIA QUE VOCÊ FICASSE MUITO À VONTADE PARA AS SUAS PALAVRAS FINAIS.

Naturalmente quero expressar o meu agradecimento especial ao Brasil e a todos aqueles brasileiros por tudo que recebi de apoio e compreensão durante meus anos de trabalhos como pesquisador estrangeiro no Brasil. Para mim foi e é uma honra especial poder trabalhar com colegas brasileiros sobre os mais diversos temas da geografia humana. As possibilidades de pesquisa nem sempre foram fáceis, mas melhoraram cada vez mais com o passar das quase seis décadas em que pesquiso sobre e no Brasil. Trabalhei nas pesquisas empregando intensa especialização e entusiasmo pessoal em um país tão magnificente com regiões tão diferenciadas sob o ponto de vista socioeconômico e ecológico. Agradeço pela amizade dos colegas brasileiros e pela constante simpatia dos colegas das mais diversas disciplinas, mas também pelos amigos brasileiros além da ciência. Muito me honrou o recebimento da "Ordem do Rio Branco" em 1986 como também a condecoração "Grã-Cruz da Ordem Nacional do Mérito Científico" em 2000, conferida em Brasília pelo Senhor Presidente 
da República do Brasil" ${ }^{14}$ Em 2001 fui nomeado membro da "Academia Brasileira de Ciências".

É muito significativo saber que meus contatos no Brasil não estão ligados somente a colegas da Geografia, mas sim nos setores inter e multidisciplinares com disciplinas que se complementam. Um bom exemplo é o seu caso que você vem desempenhando no campo da história ambiental, e que passe a ser uma referência para os trabalhos geográficos. Também suas pesquisas têm grande significado para a geografia humana. Uma referência significativa é o geógrafo alemão Leo Waibel que foi perito do Conselho Nacional de Geografia no Rio de 1946 a 1950 e iniciou seus trabalhos sobre a colonização agrária em Anápolis, Goiás em 1947, onde você, Prof. Sandro, pode dar continuidade aos antigos estudos com suas pesquisas sobre a história ambiental do Mato Grosso de Goiás e dos Cerrados.

Figura 03. Gerd Kohlhepp em sua visita a Goiás, sendo recebido na casa do entrevistador. Goiânia (GO), 2018.

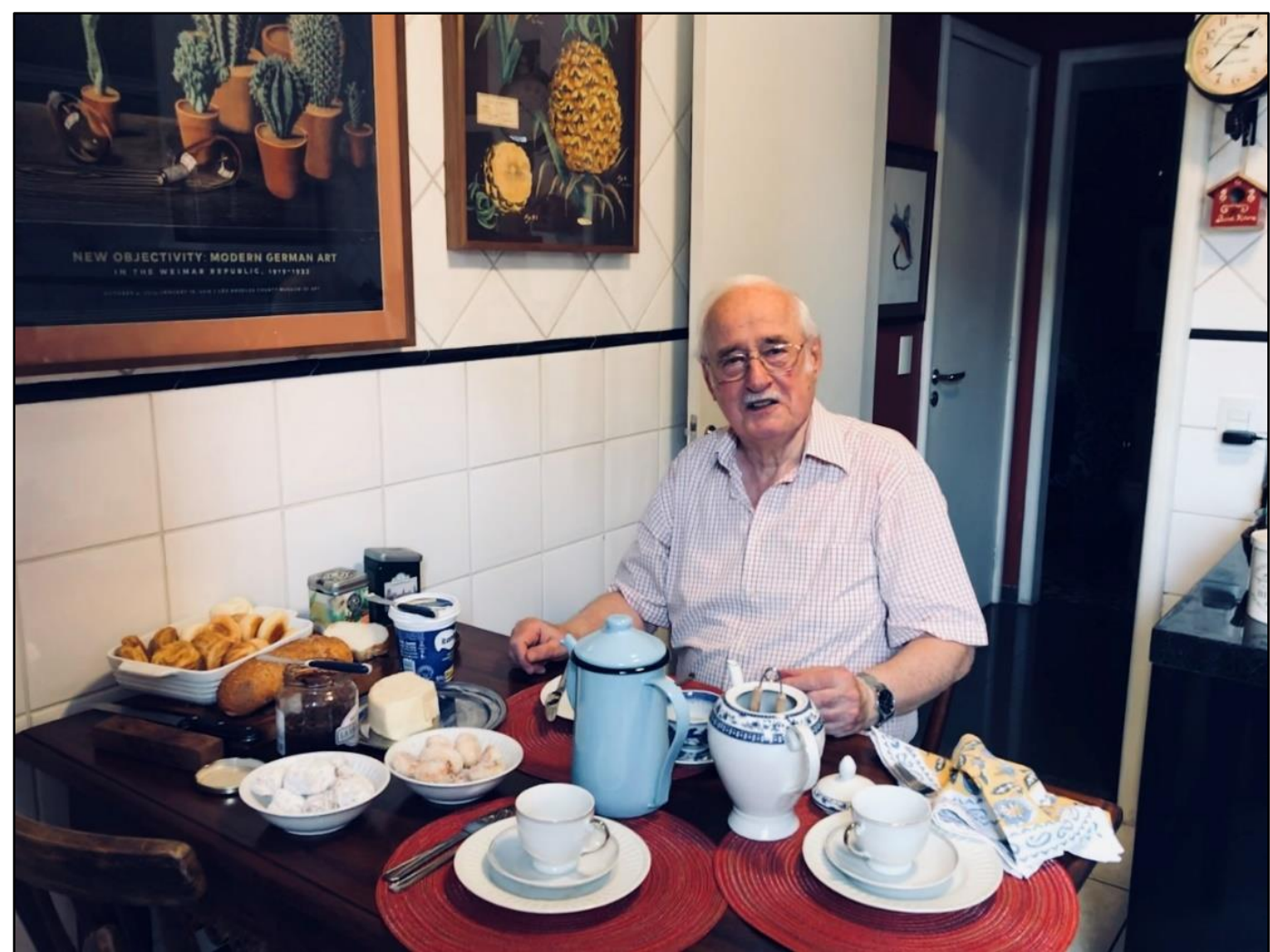

Foto: Sandro Dutra e Silva. Fonte: Arquivo pessoal do entrevistador.

14 Na época, Fernando Henrique Cardoso exercia o cargo de presidente da República, com mandato presidencial entre os anos de 1995 a 2003. 


\section{REFERENCIAS}

Bell, Stephen. Campanha Gaucha: A Brazilian Ranching System, 1850-1920. Stanford: Stanford University Press, 1998.

Carvalho, Ely Bergo de. "A Crítica Ambiental de Max von Lassberg e Reinhard Maack: Homens Do Seu Tempo." Cadernos de História 13, no. 19 (2012): 32-52. https://doi.org/10.5752/P.2237-8871.2012v13n19p32.

Dutra e Silva, Sandro. No Oeste a Terra e o Céu: A Expansão Da Fronteira Agrícola No Brasil Central. Rio de Janeiro: Mauad X, 2017.

Hitchcock, Charles B. "The Eighteenth International Geographical Congress, Rio de Janeiro, 1956." Geographical Review 47, no. 1 (1957): 118-23.

Kohlhepp, Gerd. "A Contribuição de Leo Waibel Para o Conhecimento Da Colonização Agrária No Brasil Do Séc. XX." Fronteiras: Journal of Social, Technological and Environmental Science 8, no. 3 (2019): 69-87. https://doi.org/10.21664/22388869.2019v8i3.p69-87.

---. Agrarkolonisation in Nord-Paraná. Wirtschafts- Und Sozialgeographische Entwicklungsprozesse Einer Randtropischen Pionierzone Brasiliens Unter Dem Einfluss Des Kaffeeanbaus. Vol. 41. Heidelberger Geographische Arbeiten. Wiesbaden: Franz Steiner-Verlag, 1975.

---. Colonização Agrária No Norte Do Paraná: Processos Geoeconômicos e Sociogeográficos de Desenvolvimento de Uma Zona Subtropical Do Brasil Sob a Influência Da Plantação de Café. EDUEM, 2014. https://doi.org/10.7476/9788576286554.

---. "Nas Trilhas de Leo Waibel: Pesquisas Alemãs de Geografia Humana Do Brasil de Heidelberg a Tübingen (1950-2005)." Revista Brasileira de Geografia 62, no. 2 (2018): 7-24. https://doi.org/10.21579/issn.2526-0375_2017_n2_p7-24.

Thomas Jr., William L., Carl O. Sauer, Marston Bates, and Lewis Mumford. Man's Role in Changing the Face of the Earth. Chicago: University of Chicago Press, 1956. 